\title{
Rolling contact fatigue testing of peek based composites
}

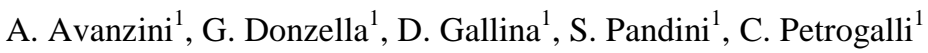 \\ ${ }^{1}$ University of Brescia, Department of Mechanical and Industrial Engineering, Italy
}

\begin{abstract}
Rolling contact fatigue phenomenon was investigated on unfilled PEEK and on three different PEEK composites: 10\% carbon micro-fiber, graphite and PTFE filled matrix, 30\% carbon micro-fiber filled matrix, 30\% glass micro-fiber filled matrix. For this aim, roller-shaped specimens were machined from extruded bars of these materials and subjected to rolling contact tests at different contact pressure levels by means of a four roller machine. Contact pressure-life diagrams and wear rates were so obtained and compared, highlighting a relationship with monotonic and hardness materials properties. Microscopic observations of contact surfaces and transversal section of the specimens also allowed observing the damage mechanisms occurred in the materials tested and the effects of the filler. In particular way, deep radial cracks appeared on unfilled PEEK, while spalling and delamination phenomena where found on composites. Diffuse microcracks were found at the filler-matrix interface of the composites specimens, confirming that the fatigue life of these materials is essentially determined by the crack propagation phase, also under rolling contact loading.
\end{abstract}

\section{Introduction}

PEEK based composites are innovative materials, obtained by introducing different filler typologies in the thermoplastic resin matrix, thus maintaining the ease of processing and lower cost associated with thermoplastics manufacturing. Most common filler typologies are carbon and glass short fibers, PTFE and graphite particles [1]; they allow enhancing specific properties as static and fatigue strength, resistance to creep and wear, mechanical and chemical stability, rigidity and toughness [2]. PEEK composites are therefore suitable for several applications in different industrial sectors, like aerospace, automotive, electrical, biomedical. Despite their increasing diffusion, the mechanical behaviour of these materials has been not fully understood, especially under cyclic loading: fatigue damage evolution and fatigue strength depend in fact strongly on microstructure and manufacturing process [3]. Very important are in this sense matrix crystallinity and molecular weight, filler tipology and correspondent interface with the matrix, fiber length, distribution and volume fraction. Attempts to propose microstructural models taking in to account these effects are limited by the problem complexity and by the difficulty in calibrating them [4-5]. Even more unknown is the behaviour of these materials when they are subjected to a rolling contact loading, although some promising applications regard components where this loading condition can be present, like bearings, gears, human prostheses and implants $[6,7,8]$ : while tribological behavior of polymers and in particular PEEK composites has been intensively studied $[9,10,11,12,13]$, rolling contact fatigue has

This is an Open Access article distributed under the terms of the Creative Commons Attribution-Noncommercial License 3.0, which permits unrestricted use, distribution, and reproduction in any noncommercial medium, provided the original work is properly cited. 
received much less attention. Most experimental studies regard unfilled polymers, like those carried out by Stolarski et al. on polystyrene (PS), polycarbonate (PC) and polymethylmetacrylate (PMMA) discs by means of a four balls machine, observing the formation of surface cracks and pits [14]. AlSabti et al. also examined the behaviour of polymethylmetacrylate (PMMA) in pure rolling and rolling-sliding condition by means of a twin-disc machine, observing the formation of crazing, surface cracks and pits on the rolling surface [15]. Other studies regard UHMWPE loaded by a cyclically moving indenter, showing pitting and delamination type surface damage mechanisms [16]. More recently, Gordon et al. analyzed unfilled polyamide and polyamide filled with aramid microfibers in sliding-rolling condition, founding respectively transversal surface cracks and flaking phenomena [17]. A general conclusion of these researches is that rolling contact condition appears to produce damage similar to that observed in metals and that thermoplastic polymers seem to sustain quite well rolling contact loading, while thermosetting polymers tend to fail in brittle manner. No systematic research has been done however in order to observe and interpret damage mechanism under rolling contact loading in relationship with material microstructure and fillers typology. In this work, the behaviour under rolling contact loading of some PEEK microfiber composites is experimentally investigated. The aim of the study is to examine the effect of the filler on the damage evolution, failure modality and material strength. In order to give an applicative meaning to the work, the research was carried out on specimens obtained from typical semi-finished products, commonly used for the construction of mechanical components.

\section{Experimental setup}

\subsection{Materials and specimens}

Four materials, supplied by Ensinger Italia, were examined in this work, specifically: unfilled grade 450G PEEK (NEAT), having glass transition temperature $\mathrm{Tg}=143{ }^{\circ} \mathrm{C}$ and melting temperature $\mathrm{Tm}=343^{\circ} \mathrm{C}$; PEEK filled with $10 \%$ carbon micro-fibers, graphite and PTFE (PVX); PEEK filled with $30 \%$ carbon micro-fibers (CF30); PEEK filled with 30\% glass (GF30) micro-fibers. Preliminary tensile tests were carried on dog-bone shaped specimens taken from extruded sheets. The results are reported in Table 1 together with material density and Vickers hardness measurements carried with a load of $25 \mathrm{~g}_{\mathrm{f}}$ and a loading time of $15 \mathrm{~s}$.

Table 1. Mechanical properties of the materials examined

\begin{tabular}{|l|c|c|c|c|c|}
\hline Material & $\begin{array}{c}\text { Elongation to } \\
\text { ropture [\%] }\end{array}$ & $\begin{array}{c}\text { Elastic modulus } \\
{[\mathbf{M P a}]}\end{array}$ & $\begin{array}{c}\text { Tensile strength } \\
{[\mathbf{M P a}]}\end{array}$ & $\begin{array}{c}\text { Density } \\
{\left[\mathbf{g} / \mathbf{c m}^{\mathbf{3}}\right]}\end{array}$ & $\begin{array}{c}\text { Hardness } \\
\mathbf{H V} / \mathbf{0 , 0 2 5}\end{array}$ \\
\hline NEAT & 15.5 & 3825 & 102 & 1.298 & 22 \\
\hline PVX & 1.8 & 4368 & 60 & 1.445 & 21 \\
\hline CF30 & 3.5 & 7812 & 117 & 1.411 & 31 \\
\hline GF30 & 3.1 & 6211 & 97 & 1.528 & 24 \\
\hline
\end{tabular}

Rolling contact tests were carried out on roller-shaped specimens, machined from extruded bars. The specimens have an inner diameter of $16 \mathrm{~mm}$, an outer diameter of $30 \mathrm{~mm}$ and thickness of $13.5 \mathrm{~mm}$.

\subsection{Test bench}

Rolling contact tests were carried out on a four roller test bench, specifically designed and constructed at the Department of Mechanical and Industrial Engineering of University of Brescia (Fig. 1). The roller-shaped specimens are mounted on pins, rotating on them and pushed against a counteracting steel disc by a pneumatic actuator and a leverage system. The steel disk is mounted on a shaft driven by an electric motor. Due to the bench configuration, the loading system is 
symmetrical, i.e. the contact force with the central disk is the same for every specimen. The maximum specimens-disk contact force is about $2 \mathrm{kN}$. Applied load is measured by a high precision load cell located along the actuator axis. Being the specimens free to rotate on the pins, the tests are carried out in pure rolling condition. A compressed air cooling system is present to regulate the specimens temperature; air flows throughout holes machined in the pins, up to the sliding interface between specimens inner surface and pins themselves. The specimens temperature can be measured during the test by an infrared pyrometer.
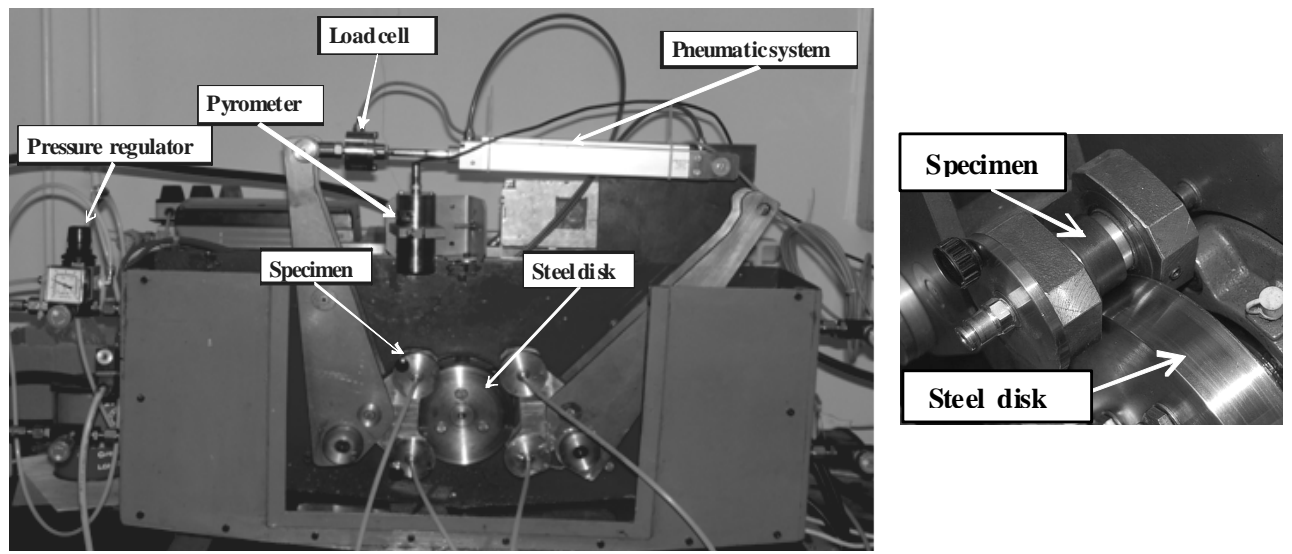

Fig.1. Rolling contact fatigue test bench with detail of the contact between polymer roller and steel disc

\subsection{Test procedure}

As mentioned above, the rolling contact tests were carried out in pure rolling and dry condition, applying a constant nominal (Hertzian) contact pressure to each specimen. Several pressure levels were considered for each material, in order to construct a correspondent pressure-life diagram. Globally, pressure levels ranged approximately from 80 to $160 \mathrm{MPa}$. Rotating speed and cooling air flow were regulated in order to guarantee a stabilized specimen temperature, (continuously measured by the pyrometer on the rolling surface) of $40^{\circ} \mathrm{C} \pm 1^{\circ} \mathrm{C}$. For this aim, rotating speed was set to 500 $\mathrm{rev} / \mathrm{min}$ for the neat PEEK and to $800 \mathrm{rev} / \mathrm{min}$ for the filled PEEKs. The tests were interrupted at the occurrence of evident surface damage (failure), or up to $10^{6}$ cycles. At the end of the test, the failed specimens were cut along a direction perpendicular to their axis (transversal section), polished and observed by optical microscope and SEM in order to investigate the crack layout, failure modality and the effect of the filler on the damage evolution. The specimens were also weighted with a precision balance at the beginning and at the end of the test, in order to evaluate the mean wear rate.

\section{Test results}

\subsection{Pressure-life diagram}

In Figure 2, the relationship between applied pressure and number of cycle to failure is shown in form of pressure-life diagram for the four materials. It can be observed a similar behaviour for NEAT and CF30 (although their damage mechanisms are very different, as reported in the following), a lower curve for PVX and a higher curve for GF30. 


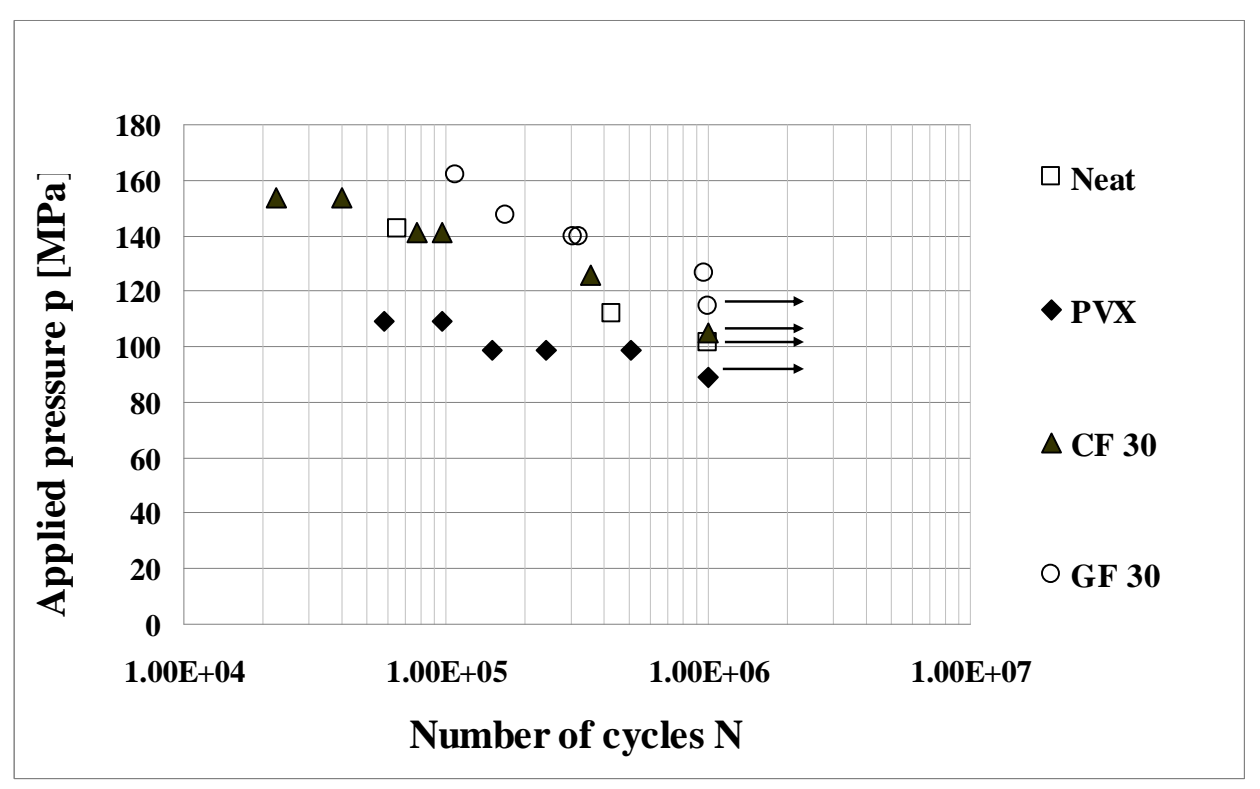

Fig.2. Pressure-life diagram

Comparing this graph with Table 1, it can be concluded that fatigue resistance of these materials shows a correspondence with their tensile strength, a part from GF30, which presents unexpectedly the highest pressure-life curve, although its static strength is lower than that of NEAT and CF30. A possible explanation of this behaviour will be given in the following.

\subsection{Wear}

For each specimen, the mean wear rate during the test has been determined in terms of removed thickness for cycle. It has been calculated as:

$$
\text { wear rate }=\frac{\Delta m}{\rho \cdot \pi \cdot d \cdot h \cdot N}
$$

where:

- $\Delta \mathrm{m}$ is the mass variation from the beginning to the end of the test;

- $\quad \rho$ is the material density;

- $\quad \mathrm{d}$ is the outer roller diameter;

- $\quad h$ is the specimen thickness;

- $\quad \mathrm{N}$ is the cycles number.

The results for the four materials examined are reported in Figure 3 as a function of the pv (pressure $\mathrm{x}$ velocity) product, in order to normalize them with respect to the test severity from a tribological point of view. A general increasing of the wear rate with pv can be observed for each material, as expected. Examining more in detail the results, a specific, quite linear trend can be recognised for each material, highlighted by the correspondent tendency lines. NEAT and PVX show a similar trend, while GF30 and CF30 presents lower tendency lines. Looking at material hardness values reported in Table 1, it can be observed an inverse relationship of wear rate with them. 


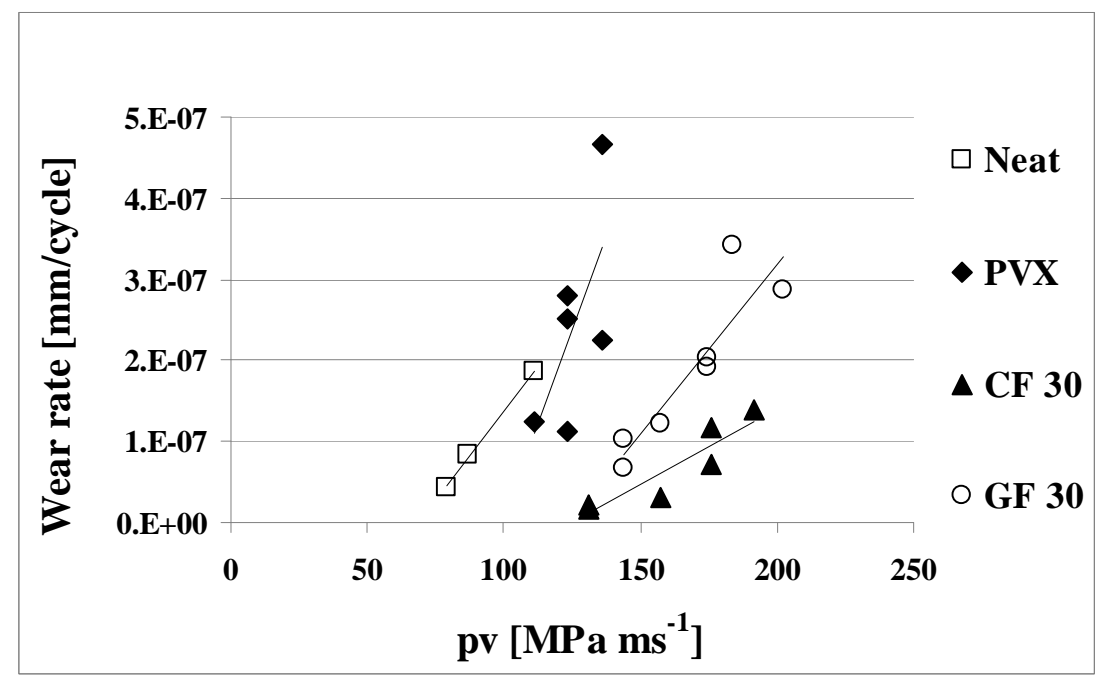

Fig.3. Mean wear rate

\subsection{Damage examination}

The rolling surfaces of four specimens, one for each examined material, at the test end are shown for comparison in Figure 4. They show the typical damage occurred.
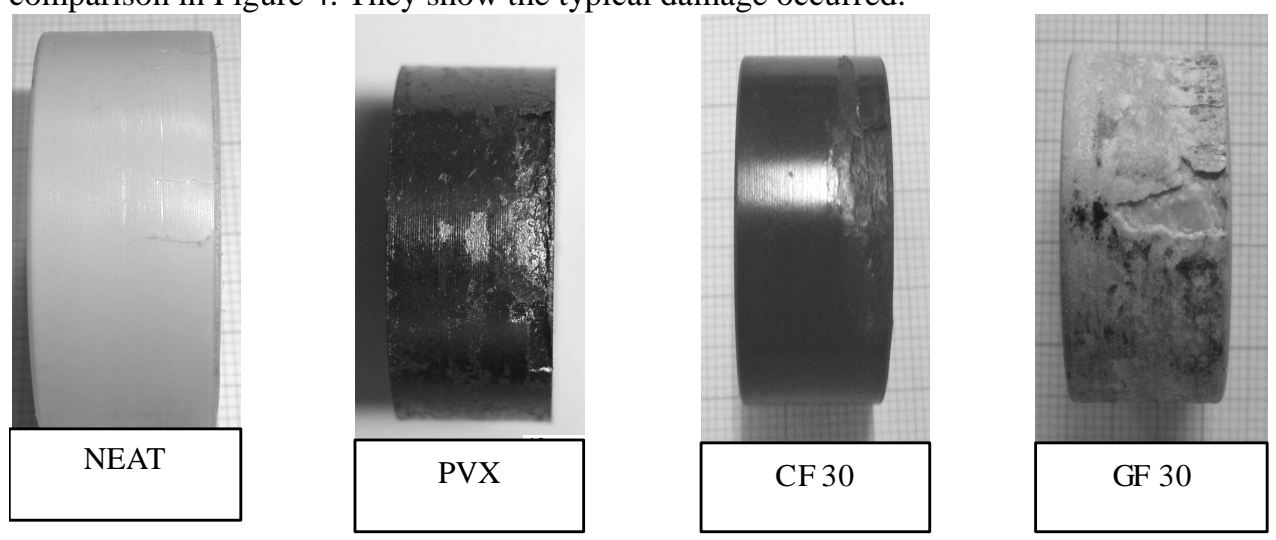

Fig.4. Rolling surface at the test end: a) NEAT, $p=142 \mathrm{MPa}, \mathrm{N}=65000$; b) $\mathrm{PVX}, \mathrm{p}=99 \mathrm{MPa}, \mathrm{N}=507000$; ) CF, $\mathrm{p}=153 \mathrm{MPa}, \mathrm{N}=40000 ; \mathrm{d}) \mathrm{GF}, \mathrm{p}=147 \mathrm{MPa}, \mathrm{N}=168000$

Evident transversal cracks are present in unfilled PEEK. On the contrary, a complex and severe surface damage layout can be observed in the three filled PEEKs, mainly appearing in form of two phenomena: delamination and spalling. The last phenomenon, similar to that typically occurring on hard steels, indicates a subsurface crack nucleation as its origin [18]. These experimental evidences recalls the results of the rolling contact tests carried out by Gordon et al. on twin-disc machine [17], who found transversal surface cracks on unfilled polyamide and flaking phenomena on the same material filled with aramid micro-fibers: although referring to different materials, this coincidence indicates a fundamental role of micro-fibers in changing failure modality. 
In the following figures, the transversal sections of the same specimens are shown. Figure 5 evidences one of the deep radial cracks found in the unfilled PEEK, corresponding to the transversal cracks visible on the rolling surface. The cause of this damage typology has to be still investigated, but from the cracks orientation it can be argued the effect of normal stresses acting in the circumferential direction, perhaps those generated by the micro-slip in the contact zone, whose detrimental effect could be favoured by the visco-elastic behaviour of the material. From the figure it can be also deduced an initial crack propagation due to fatigue, and a subsequent monotonic growth, highlighted by the evident plastic zone surrounding the crack in its final part. In effect, a similar interaction between fatigue and monotonic fracture mechanisms has been observed in unfilled PEEK during cyclic crack growth experiments on CT specimens [19].

In Figures 6 to 8 , the spalling type failure occurring in filled materials is highlighted. The pictures show in every case a similar damage layout, consisting in a macro-crack running parallel to the rolling surface, which confirms the hypothesis of subsurface origin. Orientation and depth of these macro-cracks also indicate in the orthogonal alternating shear stresses the main cause of the damage. In effect, crack depth is similar to that where these stress components are maximum, calculated as $0.5 \mathrm{~b}$ following Hertz theory (where $\mathrm{b}$ is the contact area half-width). In particular way, for the specimens shown in Figures 6, 7 and 8 the depth of the maximum orthogonal alternating shear stresses results respectively 235, 210 and 250 microns. A preferential micro-fibers orientation along the axial direction of the specimen (i.e. normal to the circumferential crack causing spalling) can be noted on GF30 specimen from Figure 8. It can explain the unexpectedly high resistance to rolling contact fatigue of this material. In fact, crack propagation along a direction perpendicular to that of the fibers is more difficult than that happening along the fibers direction, as demonstrated by crack growth tests carried out by Friedrich et al. [4] on the same material typology. A delamination mechanism on the roughness scale is also present in form of flakes, as clearly visible in Figure 7.

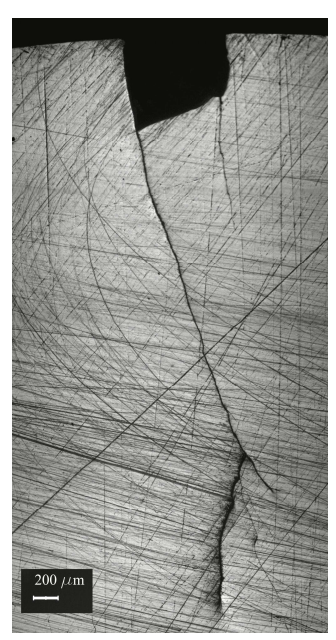

Fig.5. Transversal section of NEAT specimen ( $\mathrm{p}=142 \mathrm{MPa}, \mathrm{N}=65000)$

Observations carried out at higher magnification indicate for the composite materials the presence of a complex network of micro-cracks originating from the filler-matrix interface and creating a path along which the main crack proceeds. Some examples are reported in Figure 9 for PVX specimen. This confirms the results of previous researchers on fatigue of PEEK composites, which clearly showed early and diffused micro-crack nucleation from matrix-filler interface, due to the related stress concentration effect [20]: these type of materials can be therefore considered intrinsically notched and their fatigue life is almost totally determined by crack propagation phase, being on the other hand their resistance to crack growth higher then that of the unfilled material. 


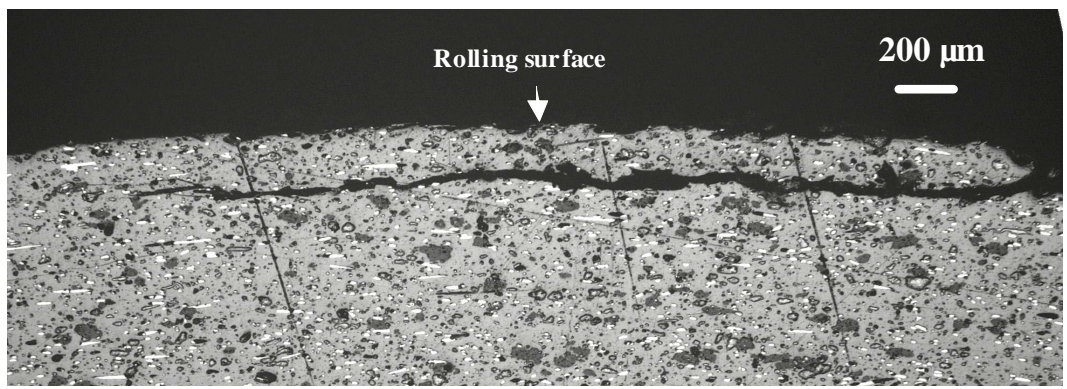

Fig.6. Transversal section of PVX specimen ( $\mathrm{p}=99 \mathrm{MPa}, \mathrm{N}=507000)$

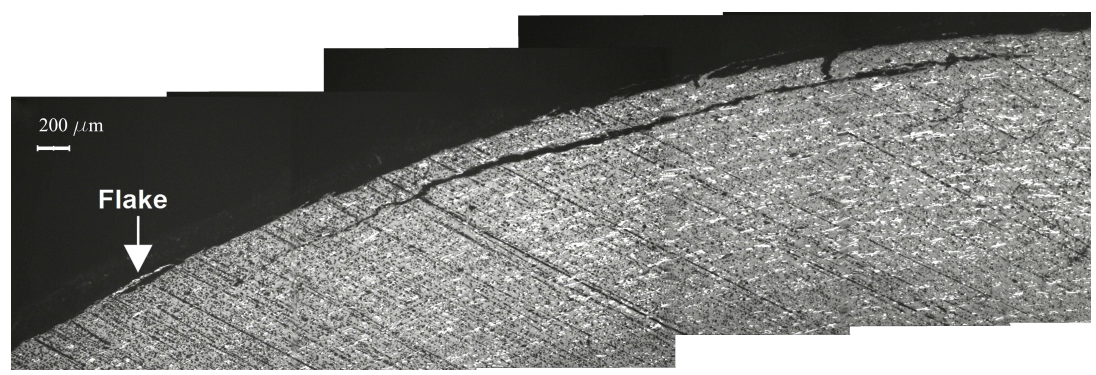

Fig.7. Transversal section of $\mathrm{CF} 30$ specimen ( $\mathrm{p}=153 \mathrm{MPa}, \mathrm{N}=40000)$

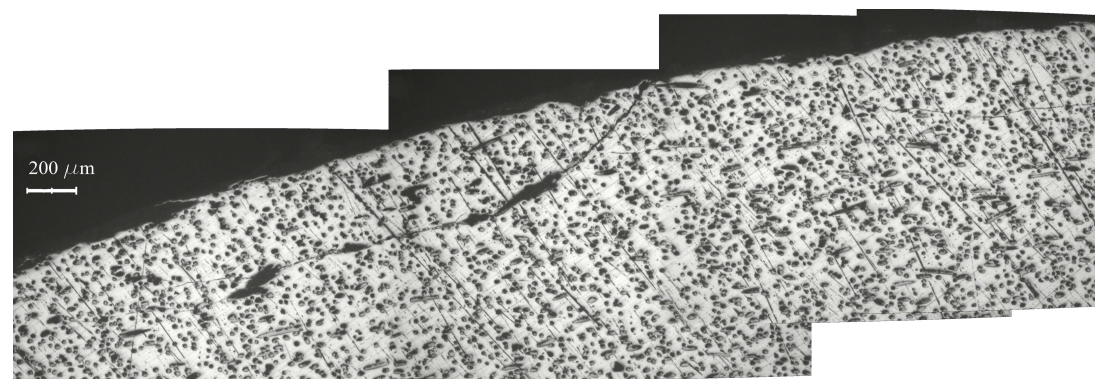

Fig.8. Transversal section of GF30 specimen ( $\mathrm{p}=147 \mathrm{MPa}, \mathrm{N}=168000)$
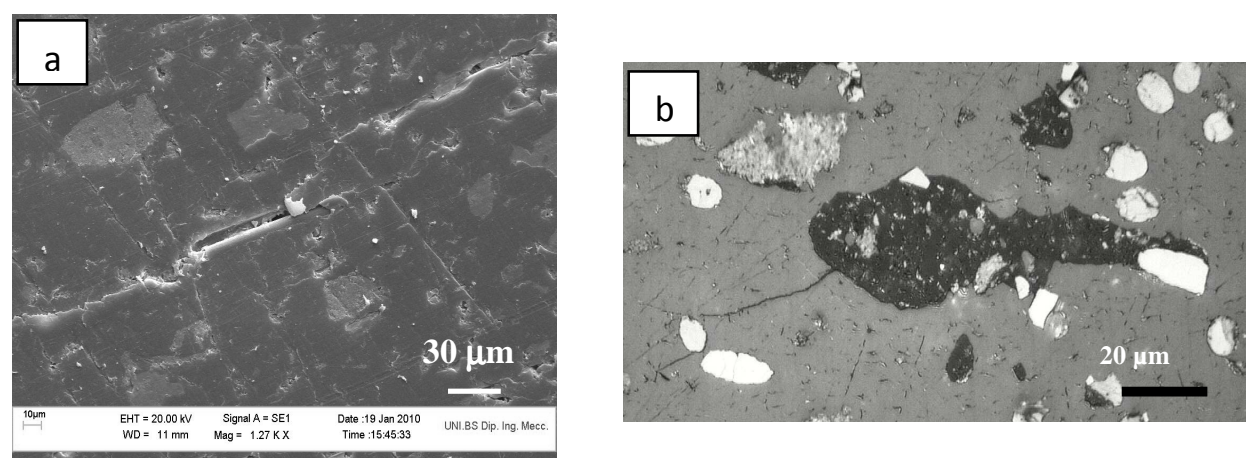

Fig.9. Transversal section of PVX specimen ( $p=99 \mathrm{MPa}, \mathrm{N}=507000$ ): fibre debonding and emanating cracks a), example of micro-crack emanating from the interface between matrix and a graphite particle $b$ ) 


\section{Conclusions}

Rolling contact fatigue tests were carried out on unfilled PEEK and three different PEEK composites, by means of roller-shaped specimens taken from extruded bars. Contact pressure-life diagrams were obtained, evidencing a relationship between static and rolling contact fatigue strength, a part from the $30 \%$ glass reinforced specimens, which showed an unexpectedly high fatigue resistance imputed to a preferential and favourable micro-fibers orientation. Mean wear rate of the tested specimens was also determined, which relates inversely to materials hardness. Rolling contact fatigue damage results very different for unfilled and filled specimens: it appears in form of deep radial cracks for the first ones, imputed to the presence of tensile circumferential stresses due to the microslips in the contact zone; on the contrary, main severe spalling phenomena similar to those observed in steels were observed in filled specimens, indicating a subsurface origin due to orthogonal alternating shear stresses. A network of microcraks nucleated at the filler-matrix interface has been also observed, confirming the intrinsically notched character of these materials, whose fatigue life is therefore essentially determined by the crack propagation phase.

\section{Acknoledgements}

The work has been carried out as a part of the project AMDACOMP, financed by the Italian University and Research Ministry PRIN2007 grant. The authors wish also to thank Ing. Andrea Rossetti and Mr Stefano Debbia from Ensinger Italia, for their kind support to the research.

\section{References}

1. Thermoplastic resins, ASM Handbook, Vol. 21, Composites, Asm Int. (2002)

2. J.R. Sarasua et al., Journal of Materials Science, 30, 3501-3508, (1995)

3. K.S. Saib et al., Materials and Manufacturing Processes, 9, 829-850, (1994)

4. K. Friedrich, R. Wlater, H. Voss, J. Karger-Kocsis, Composites, 17, 205-216, (1986)

5. W.J. Evans, D.H. Isaac, K.S. Saib, Composites Part A, 27A, 547-554, (1996)

6. M. Kurokawa et al., Tribology International, 32, 491-497, (1999)

7. S.M. Kurtz, J.M. Devinec, Biomaterials, 28, 4845-4869, (2007)

8. A. Wang et al., Wear, 225-229,724-7, (1999)

9. T.A. Stolarski, Wear, 158,71-8, (1992)

10. Z. Lu, K. Friedrich, Wear, 181-183, 624-31, (1995)

11.Z. Zhang et al., Tribology International, 37, 271-277, (2004)

12. W. Hufenbach, K. Kunze, J. Bijwe, Journal of synthetic lubrication, 20, 227-240, (2003)

13. B. Lal, G. Narayan Mathur, Journal of synthetic lubrication, 24, 149-166, (2007)

14. T.A. Stolarski et al., Wear, 214, 271-278, (1998)

15. S.I. Al-Sabti, T.A. Stolarski, Tribology International, 31, 695-699, (1998)

16. J.A. Estupinan et al., J Orth Res, 16, 80-88, (1998)

17. D.H. Gordon, S.N. Kukureka, Wear, 267, 669-678, (2009)

18. G. Donzella, M. Faccoli, A. Mazzù, C. Petrogalli, H. Desimone, International Conference on Crack Paths CP2009, Vicenza, September 23-25, (2009)

19. K.S. Saib, W.J. Evans, D.H. Isaac, Polymer, 34, 3198-3203, (1993)

20. H. Nisitani, H. Noguchi, Y.H. Kim, Engineering Fracture Mechanics, 43, 685-705, (1992) 